\title{
FORMAÇÃO DE PROFESSORES NO BRASIL: CARACTERÍSTICAS E PROBLEMAS
}

\author{
Bernardete A. GatTi
}

\begin{abstract}
RESUMO: Este artigo aborda a formação de professores no Brasil, considerando quatro aspectos: o da legislação relativa a essa formação; as características sócio-educacionais dos licenciandos; as características dos cursos formadores de professores; os currículos e ementas de licenciaturas em Pedagogia, Língua Portuguesa, Matemática e Ciências Biológicas. Os três últimos aspectos são tratados a partir de pesquisas publicadas nos anos de 2008 e 2009. A interação dos diferentes fatores abordados sinaliza um cenário preocupante sobre a resultante dessa formação. Mereceriam maior atenção as ambiguidades das normatizações vigentes, a fragmentação da formação entre e intracurso, a parte curricular dedicada à formação específica para o trabalho docente, aqui incluídos os estágios na forma como hoje se apresentam na maioria das instituiçôes.
\end{abstract}

Palavras-chave: Formação de professores. Legislação. Licenciaturas. Currículo. Estágios.

\section{TEACHERS' EDUCATION IN BRAZIL: CHARACTERISTICS AND PROBLEMS}

ABSTRACT: This paper examines teachers' education in Brazil considering four aspects: the legislation on teacher training; the socio-educational characteristics of the students; the main features of the teacher training courses; the curriculum and programs of Pedagogy, Portuguese, Mathematics and Biology teacher training. The last three aspects are treated according to research produced

Doutora em Psicologia e coordenadora do Departamento de Pesquisas Educacionais da Fundação Carlos Chagas (FCC). E-mail: gatti@fcc.org.br 
between 2008 and 2009. The interaction of these different aspects points out a worrisome scenario as for the results of such education. The ambiguities of existing norms, the fragmentation between and within teacher training courses and the part of curriculum devoted to building specific skills and knowledge for teaching practice deserve more attention from universities providing teachers' education.

Key words: Teachers' education. Legislation. Curriculum. Teacher training.

\section{Introdução}

$F$ azendo uma pequena digressão histórica sobre a formação de professores no Brasil, lembramos que a formação de docentes para o ensino das "primeiras letras" em cursos específicos foi proposta no final do século XIX com a criação das Escolas Normais. Estas correspondiam à época ao nível secundário e, posteriormente, ao ensino médio, a partir de meados do século XX. Continuaram a promover a formação dos professores para os primeiros anos do ensino fundamental e a educação infantil até recentemente, quando, a partir da Lei n. 9.394 de 1996, postula-se a formação desses docentes em nível superior, com um prazo de dez anos para esse ajuste. É no início do século $\mathrm{XX}$ que se dá o aparecimento manifesto da preocupação com a formação de professores para o "secundário" (correspondendo aos atuais anos finais do ensino fundamental e ao ensino médio), em cursos regulares e específicos. Até então, esse trabalho era exercido por profissionais liberais ou autodidatas, mas há que considerar que o número de escolas secundárias era bem pequeno, bem como o número de alunos. No final dos anos de 1930, a partir da formação de bacharéis nas poucas universidades entáo existentes, acrescenta-se um ano com disciplinas da área de educação para a obtenção da licenciatura, esta dirigida à formação de docentes para o "ensino secundário" (formação que veio a denominar-se popularmente " $3+1$ "). Esse modelo veio se aplicar também ao curso de Pedagogia, regulamentado em 1939, destinado a formar bacharéis especialistas em educação e, complementarmente, professores para as Escolas Normais em nível médio. Os formados neste curso também teriam, por extensão e portaria ministerial, a possibilidade de lecionar algumas disciplinas no ensino secundário. No ano 
de 1986, o então Conselho Federal de Educação aprova o Parecer n. 161, sobre a Reformulação do Curso de Pedagogia, que faculta a esses cursos oferecer também formação para a docência de $1^{\text {a }}$ a $4^{\mathrm{a}}$ séries do ensino fundamental, o que algumas instituições já vinham fazendo experimentalmente. Foram, sobretudo, as instituições privadas que se adaptaram para oferecer este tipo de formação ao final dos anos de 1980. A grande maioria dos cursos de Pedagogia das instituições públicas manteve sua vocação de formar bacharéis, nos moldes da origem desses cursos.

Com a publicação da Lei n. 9.294/96 - Lei de Diretrizes e Bases da Educação Nacional - em dezembro de 1996, alterações são propostas tanto para as instituições formadoras como para os cursos de formação de professores, tendo sido definido período de transição para efetivação de sua implantação. Em 2002, as Diretrizes Curriculares Nacionais para a Formação de Professores são promulgadas e, nos anos subsequentes, as Diretrizes Curriculares para cada curso de licenciatura passam a ser aprovadas pelo Conselho Nacional de Educação. Mesmo com ajustes parciais em razão das novas diretrizes, verifica-se nas licenciaturas dos professores especialistas a prevalência da histórica ideia de oferecimento de formação com foco na área disciplinar específica, com pequeno espaço para a formação pedagógica. Adentramos o século XXI em uma condição de formação de professores nas áreas disciplinares em que, mesmo com as orientaçóes mais integradoras quanto à relação "formação disciplinar/formação para a docência", na prática ainda se verifica a prevalência do modelo consagrado no início do século $\mathrm{XX}$ para essas licenciaturas, como veremos adiante.

Quanto aos cursos de graduação em Pedagogia, somente em 2006, depois de muitos debates, o Conselho Nacional de Educação aprovou a Resolução n. 1, de 15/05/2006, com as Diretrizes Curriculares Nacionais para esses cursos, propondo-os como licenciatura e atribuindo a estes a formação de professores para a educação infantil e anos iniciais do ensino fundamental, bem como para o ensino médio na modalidade Normal, onde fosse necessário e onde esses cursos existissem, e para a educação de jovens e adultos, além da formação de gestores. Essa licenciatura passa a ter amplas atribuições, embora tenha como eixo a formação de docentes para os anos iniciais da escolarização. A complexidade curricular exigida para esse curso é grande, notando-se também, pelas orientações da Resolução citada, a dispersão 
disciplinar que se impõe em função do tempo de duração do curso e sua carga horária, dado que ele deverá propiciar: "a aplicação ao campo da educação, de contribuiçôes, entre outras, de conhecimentos como o filosófico, o histórico, o antropológico, o ambiental-ecológico, o psicológico, o linguístico, o sociológico, o político, o econômico, o cultural"; englobar (art. $4^{\circ}$, parágrafo único) a formação de habilidades de planejamento, execução, coordenação, acompanhamento e avaliação de tarefas próprias do setor da Educação, de projetos e experiências educativas não escolares; a produção e difusão do conhecimento científico-tecnológico do campo educacional, em contextos escolares e não escolares. O licenciado em Pedagogia deverá ainda: estar apto no que é especificado em mais dezesseis incisos do artigo $5^{\circ}$, dessa Resolução, e cumprir estágio curricular em conformidade ao inciso IV, do artigo $8^{\circ}$. Estas postulações criaram tensões e impasses para o desenvolvimento curricular desses cursos, ainda não bem equacionadas. Enfeixar todas essas orientaçôes em uma matriz curricular, especialmente para as classes noturnas onde se encontra a maioria dos alunos desses cursos, não é tarefa fácil. De qualquer modo, o que se verifica é que a formação de professores para a educação básica é feita, em todos os tipos de licenciatura, de modo fragmentado entre as áreas disciplinares e níveis de ensino, não contando o Brasil, nas instituições de ensino superior, com uma faculdade ou instituto próprio, formador desses profissionais, com uma base comum formativa, como observado em outros países, onde há centros de formação de professores englobando todas as especialidades, com estudos, pesquisas e extensão relativos à atividade didática e às reflexôes e teorias a ela associadas. Lembremos também que, historicamente, nos cursos formadores de professores esteve desde sempre colocada a separação formativa entre professor polivalente - educação infantil e primeiros anos do ensino fundamental - e professor especialista de disciplina, como também para estes ficou consagrado o seu confinamento e dependência aos bacharelados disciplinares. Essa diferenciação, que criou um valor social - menor/maior - para o professor polivalente, para as primeiras séries de ensino, e o professor "especialista", para as demais séries, ficou histórica e socialmente instaurada pelas primeiras legislações no século XXI, e é vigente até nossos dias, tanto nos cursos, como na carreira e salários e, sobretudo, 
nas representações da comunidade social, da acadêmica e dos políticos, mesmo com a atual exigência de formação em nível superior dos professores dos anos iniciais da educação básica. Qualquer inovação na estrutura de instituiçôes e cursos formadores de professores esbarra nessa representação tradicional e nos interesses instituídos, o que tem dificultado repensar e reestruturar essa formação de modo mais integrado e em novas bases.

\section{Licenciaturas, profissionalidade e profissionalização}

As licenciaturas são cursos que, pela legislação, têm por objetivo formar professores para a educação básica: educação infantil (creche e pré-escola); ensino fundamental; ensino médio; ensino profissionalizante; educação de jovens e adultos; educação especial. Sua institucionalização e currículos vêm sendo postos em questão, e isso não é de hoje. Estudos de décadas atrás já mostravam vários problemas na consecução dos propósitos formativos a elas atribuídos (Candau, 1987; Braga, 1988; Alves, 1992; Marques, 1992). Hoje, em função dos graves problemas que enfrentamos no que respeita às aprendizagens escolares em nossa sociedade, a qual se complexifica a cada dia, avoluma-se a preocupação com as licenciaturas, seja quanto às estruturas institucionais que as abrigam, seja quanto aos seus currículos e conteúdos formativos. Deve ser claro para todos que essa preocupação não quer dizer reputar apenas ao professor e à sua formação a responsabilidade sobre o desempenho atual das redes de ensino. Múltiplos fatores convergem para isso: as políticas educacionais postas em ação, o financiamento da educação básica, aspectos das culturas nacional, regionais e locais, hábitos estruturados, a naturalização em nossa sociedade da situação crítica das aprendizagens efetivas de amplas camadas populares, as formas de estrutura e gestão das escolas, formação dos gestores, as condiçỗes sociais e de escolarização de pais e mães de alunos das camadas populacionais menos favorecidas (os "sem voz") e, também, a condição do professorado: sua formação inicial e continuada, os planos de carreira e salário dos docentes da educação básica, as condições de trabalho nas escolas.

Mesmo considerando essa conjunção de fatores, pensamos ser importante chamar a atenção para a questão específica da formação inicial 
dos professores, o que envolve diretamente as instituiçóes de ensino superior, em especial as universidades. Abordaremos a questão a partir de dados de pesquisa. Procura-se contribuir para o debate que busca a melhoria da qualidade da formação desses profissionais, tão essenciais para a nação e para propiciar, nas escolas e nas salas de aula do ensino básico, melhores oportunidades formativas para as futuras geraçôes. Estamos assumindo que o papel da escola, e dos professores, é o de ensinar-educando, uma vez que postulamos que sem conhecimentos básicos para interpretação do mundo não há verdadeira condição de formação de valores e de exercício de cidadania.

Trataremos das questôes relativas às licenciaturas a partir de duas pesquisas que coordenamos sobre a formação dos docentes, trazendo à discussão dados sobre as condições de oferta desses cursos, suas características, as características dos licenciandos e suas condições de profissionalidade (Gatti et al., 2008, v. 1 e 2; Gatti \& Nunes, 2009; Gatti \& Barreto, 2009). Entendemos, com Ramalho, Nuñez e Gauthier (2003), que a profissionalidade é o conjunto de características de uma profissão que enfeixam a racionalização dos conhecimentos e habilidades necessárias ao exercício profissional, e que a profissionalização de professores implica a obtenção de um espaço autônomo, próprio à sua profissionalidade, com valor claramente reconhecido pela sociedade. Não há consistência em uma profissionalização sem a constituição de uma base sólida de conhecimentos e formas de ação. Com estas conceituações, estamos saindo do improviso, da ideia do professor missionário, do professor quebra-galho, do professor artesão, ou tutor, do professor meramente técnico, para adentrar a concepção de um profissional que tem condiçôes de confrontar-se com problemas complexos e variados, estando capacitado para construir soluçôes em sua ação, mobilizando seus recursos cognitivos e afetivos. Como afirmam os autores citados: "A profissionalização é acompanhada por uma autonomia crescente, por elevação do nível de qualificação, uma vez que a aplicação de regras exige menos competência do que a construção de estratégias" (2003, p. 61).

\section{Contexto dos cursos e características dos licenciandos}

Observando o crescimento relativo dos cursos de formação de professores, entre 2001 e 2006, verifica-se que a oferta de cursos de 
Pedagogia, destinados à formação de professores polivalentes, praticamente dobrou (94\%). As demais licenciaturas tiveram um aumento menor nessa oferta, cerca de $52 \%$. Porém, o crescimento proporcional de matrículas ficou bem aquém: aumento de $37 \%$ nos cursos de Pedagogia e $40 \%$ nas demais licenciaturas. As universidades respondem por $63 \%$ desses cursos e, quanto ao número de matriculados, a maior parte está nas instituiçōes privadas: $64 \%$ das matrículas em Pedagogia e $54 \%$ das matrículas nas demais licenciaturas (Gatti \& Barreto, 2009).

Destacamos um dado que nos remete a pensar nas condiçóes do tipo de demanda para esses cursos, na forma de oferta das licenciaturas, sua estrutura, sua dinâmica curricular, suas formas de institucionalização: chama a atenção o baixo nível de conclusão nesses cursos, que se situava na taxa média de $24 \%$, conforme dados do INEP/ MEC (2006). O Censo da Educação Superior de 2007 oferece, por sua vez, outro indício importante: o número de matrículas nos cursos voltados especificamente para as disciplinas do magistério, os chamados cursos de Formação de Professores de Disciplinas Específicas, foi menor em 2007 do que em 2006 no caso de algumas disciplinas, sendo que estes cursos, no nível superior, foram os únicos que apresentaram números negativos de crescimento no país.

Quais as características dos alunos das licenciaturas? É importante considerar as características dos licenciandos, uma vez que estas têm peso sobre as aprendizagens e seus desdobramentos na atuação profissional. Quem são os alunos das licenciaturas? Quais expectativas têm, qual sua bagagem?

No estudo de Gatti e Barreto (2009), em que se toma por base o questionário socioeconômico do Exame Nacional de Cursos (ENADE, 2005), abrangendo 137.001 sujeitos, mostra-se que, quando os alunos das licenciaturas são indagados sobre a principal razão que os levou a optar pela licenciatura, $65,1 \%$ dos alunos de Pedagogia atribuem a escolha ao fato de querer ser professor, ao passo que esse percentual cai para aproximadamente a metade entre os demais licenciandos. A escolha da docência como uma espécie de "seguro desemprego", ou seja, como uma alternativa no caso de não haver possibilidade de exercício de outra atividade, é relativamente alta (21\%), sobretudo entre os licenciandos de outras áreas que não a Pedagogia (ver Tabela 1 , a seguir): 


\section{Tabela 1}

Principal razão da escolha por licenciatura (ENADE, 2005)

\begin{tabular}{|c|l|c|c|c|c|c|c|}
\cline { 3 - 7 } \multicolumn{2}{c|}{} & \multicolumn{2}{c|}{ Pedagogia } & \multicolumn{2}{c|}{ Licenciaturas } & \multicolumn{2}{c|}{ Total } \\
\cline { 3 - 8 } \multicolumn{2}{l|}{} & $\mathrm{N}$ & $\%$ & $\mathrm{~N}$ & $\%$ & $\mathrm{~N}$ & $\%$ \\
\hline (A) & Porque quero ser professor & 25.625 & 65,1 & 47.469 & 48,6 & 73.094 & 53,4 \\
\hline (B) & $\begin{array}{l}\text { Para ter outra opção se não conseguir exercer } \\
\text { outro tipo de atividade }\end{array}$ & 5.222 & 13,3 & 23.319 & 23,9 & 28.541 & 20,8 \\
\hline (C) & Por influência da família & 2.036 & 5,2 & 3.374 & 3,5 & 5.410 & 3,9 \\
\hline (D) & $\begin{array}{l}\text { Porque tive um bom professor que me serviu } \\
\text { de modelo }\end{array}$ & 2.595 & 6,6 & 13.265 & 13,6 & 15.860 & 11,6 \\
\hline (E) & Eu não quero ser professor & 1.898 & 4,8 & 5.174 & 5,3 & 7.072 & 5,2 \\
\hline (F) & É o único curso próximo da minha residência & 1.153 & 2,9 & 3.684 & 3,8 & 4.837 & 3,5 \\
\hline & Branco & 784 & 2,0 & 1.260 & 1,3 & 2.044 & 1,5 \\
\hline & Respostas inválidas & 46 & 0,1 & 97 & 0,1 & 143 & 0,1 \\
\hline
\end{tabular}

Fonte: MEC/INEP/DEAES - ENADE (2005).

Quanto à idade, encontrou-se menos da metade do conjunto dos licenciandos na faixa etária ideal, de 18 a 24 anos (46\%), dado não esperado; entre 25 a 29 anos situam-se pouco mais de $20 \%$ deles e proporção semelhante está na faixa dos 30 a 39 anos. É possível, porém, fazer uma distinção entre os estudantes de Pedagogia e os alunos das demais licenciaturas: os primeiros tendem a ser mais velhos. Enquanto apenas 35\% dos alunos de Pedagogia estão na faixa ideal de idade para o curso, essa proporção aumenta para os estudantes das demais licenciaturas, sendo que entre os alunos de Letras e da área de Humanas a proporção na faixa ideal está em torno de $45 \%$ e, para os da área de Ciências e Matemática, fica entre $51 \%$ e 65\%. Os alunos de Pedagogia são também mais numerosos nas faixas etárias dos mais velhos, no intervalo de 30 a 39 anos, ou acima de 40 anos.

Quanto ao sexo, como já sabido, há uma feminização da docência: $75,4 \%$ dos licenciandos são mulheres, e este não é fenômeno recente. Desde a criação das primeiras Escolas Normais, no final do século XIX, as mulheres começaram a ser recrutadas para o magistério das primeiras letras. A própria escolarização de nível médio da mulher se deu pela expansão dos cursos de formação para o magistério, permeados pela representação do ofício docente como prorrogação 
das atividades maternas e pela naturalização da escolha feminina pela educação (Gatti \& Barreto, op. cit, p. 62).

Entre os estudantes dos cursos de nível superior para a docência, $50,4 \%$ situam-se nas faixas de renda familiar média, cujo intervalo é de três a dez salários mínimos. Ligeiras variações favorecem os estudantes das demais licenciaturas, em relação aos alunos de Pedagogia nas diferentes faixas salariais superiores. Observa-se, entretanto, uma clara inflexão em direção à faixa de renda mais baixa. É muito expressivo o percentual de alunos com renda familiar de até três salários mínimos $(39,2 \%)$ e escassa a frequência de sujeitos nas faixas de renda acima de dez salários mínimos.

\section{Tabela 2}

Licenciandos segundo a faixa etária - ENADE (2005)

\begin{tabular}{|l|c|c|c|c|c|c|}
\cline { 2 - 7 } \multicolumn{1}{c|}{} & Até $\mathbf{2 4}$ & $\mathbf{2 5}$ a 29 & $\mathbf{3 0}$ a 39 & $\mathbf{4 0}$ a 49 & $\mathbf{5 0}$ a 64 & $\mathbf{6 5}$ ou mais \\
\cline { 2 - 7 } \multicolumn{1}{c|}{} & $\%$ & $\%$ & $\%$ & $\%$ & $\%$ & $\%$ \\
\hline Pedagogia & 34,8 & 21,9 & 26,6 & 13,7 & 3,0 & 0,1 \\
\hline Biologia & 66,4 & 17,6 & 11,3 & 4,1 & 0,7 & 0,0 \\
\hline Física & 61,6 & 22,3 & 11,3 & 3,9 & 0,8 & 0,0 \\
\hline Geografia & 48,5 & 22,0 & 21,6 & 9,5 & 2,0 & 0,0 \\
\hline História & 45,9 & 21,2 & 21,0 & 9,6 & 2,4 & 0,1 \\
\hline Letras & 46,1 & 21,6 & 21,1 & 8,8 & 2,0 & 0,0 \\
\hline Matemática & 51,6 & 20,1 & 19,6 & 7,2 & 1,4 & 0,0 \\
\hline Química & 56,9 & 24,5 & 14,0 & 4,0 & 0,6 & 0,0 \\
\hline Total & 46,5 & 21,1 & 20,9 & $\mathbf{9 , 4}$ & $\mathbf{2 , 1}$ & $\mathbf{0 , 0}$ \\
\hline
\end{tabular}

Fonte: MEC/INEP. Questionário socioeconômico - ENADE (2005).

No que se refere à bagagem cultural anterior, a escolaridade dos pais pode ser tomada como um indicador importante da bagagem cultural das famílias de que provêm os estudantes. Em um país de escolarização tardia como o Brasil, em torno de 10\% deles são oriundos de lares de pais analfabetos e, se somados estes aos que têm pais que frequentaram apenas até a $4^{\text {a }}$ série do ensino fundamental, chega-se 
aproximadamente à metade dos alunos, o que denota um claro processo de ascensão desse grupo geracional aos mais altos níveis de formação. Observa-se, contudo, que há também uma proporção, que não é tão pequena para os padróes de escolaridade da população, de alunos que possuem pais com instrução de nível médio. Pais e mães dos estudantes de Pedagogia são sistematicamente menos escolarizados que os dos demais cursos.

\section{Tabela 3}

Licenciandos: renda mensal da família - ENADE (2005)

\begin{tabular}{|c|l|c|c|c|c|c|c|}
\cline { 3 - 8 } \multicolumn{2}{c|}{} & \multicolumn{2}{c|}{ Pedagogia } & \multicolumn{2}{c|}{ Licenciaturas } & \multicolumn{2}{c|}{ Total } \\
\cline { 3 - 8 } \multicolumn{2}{c|}{} & $\mathbf{n}$ & $\%$ & $\mathbf{N}$ & $\%$ & $\mathbf{n}$ & $\%$ \\
\hline (A) & Até 3 salários mínimos & 16.473 & 41,9 & 37.237 & 38,1 & 53.710 & 39,2 \\
\hline (B) & De 3 a 10 salários mínimos & 19.340 & 49,1 & 49.758 & 51,0 & 69.098 & 50,4 \\
\hline (C) & De 11 a 20 salários mínimos & 2.483 & 6,3 & 7.564 & 7,7 & 10.047 & 7,3 \\
\hline (D) & De 21 a 30 salários mínimos & 496 & 1,3 & 1.599 & 1,6 & 2.095 & 1,5 \\
\hline (E) & Mais de 30 salários mínimos & 221 & 0,6 & 791 & 0,8 & 1.012 & 0,7 \\
\hline & Branco & 295 & 0,7 & 581 & 0,6 & 876 & 0,6 \\
\hline & Respostas inválidas & 51 & 0,1 & 112 & 0,1 & 163 & 0,1 \\
\hline
\end{tabular}

Fonte: MEC/INEP. Questionário socioeconômico - ENADE (2005).

Como se vê pela Tabela 5, os estudantes provêm, em sua maioria, da escola pública. São $68,4 \%$ os que cursaram todo o ensino médio no setor público e $14,2 \%$ os que o fizeram parcialmente. A proporção de alunos que frequentaram apenas o ensino médio privado é menor entre os alunos da Pedagogia $(14,3 \%)$ do que entre os das demais licenciaturas $(18,3 \%)$. O percentual de estudantes que procedem do supletivo situa-se em torno de $6 \%$ nos dois grupos. Considerando como referência de desempenho escolar anterior ao ensino superior dos alunos de escola pública, os resultados no Exame Nacional do Ensino Médio (ENEM) - mesmo considerando a não paridade total com o grupo de licenciandos -, em que a média obtida por esses alunos foi, em 2006, de 34,94 pontos e, em 2008, de 37,27 pontos, em 100 possíveis, verificamos que a escolaridade 
anterior realizada em escola pública evidencia grandes carências nos domínios de conhecimentos básicos. É com esse cabedal que a maioria dos licenciandos adentra nos cursos de formação de professores.

\section{Tabela 4}

Licenciandos: escolaridade dos pais

\begin{tabular}{|c|c|c|c|c|c|c|c|}
\hline & \multicolumn{2}{|c|}{ Pedagogia } & \multicolumn{2}{|c|}{ Licenciaturas } & \multicolumn{2}{|c|}{ Total } \\
\hline & & $\mathrm{N}$ & $\%$ & $\mathbf{n}$ & $\%$ & $\mathbf{n}$ & $\%$ \\
\hline (A) & Nenhuma escolaridade & 4.326 & 11,0 & 8.196 & 8,4 & 12.522 & 9,1 \\
\hline (B) & Ensino fundamental: de $1^{\underline{a}}$ a $4^{\underline{a}}$ série & 18.303 & 46,5 & 38.587 & 39,5 & 56.890 & 41,5 \\
\hline (C) & Ensino fundamental: de $5^{\underline{a}}$ a $8^{\underline{a}}$ série & 6.203 & 15,8 & 17.371 & 17,8 & 23.574 & 17,2 \\
\hline (D) & Ensino médio & 7.240 & 18,4 & 22.151 & 22,7 & 29.391 & 21,5 \\
\hline (E) & Ensino superior & 2.982 & 7,6 & 10.583 & 10,8 & 13.565 & 9,9 \\
\hline & Branco & 255 & 0,6 & 648 & 0,7 & 903 & 0,7 \\
\hline & Respostas inválidas & 50 & 0,1 & 106 & 0,1 & 156 & 0,1 \\
\hline
\end{tabular}

Fonte: MEC/INEP. Questionário socioeconômico - ENADE (2005).

Vale destacar dois aspectos relativos aos cursos que frequentam, os quais se compõem com as características dos licenciandos e as dos currículos para definir o cenário da constituição profissional: os materiais que mais utilizaram no curso e as avaliações no curso. Apostilas, resumos e cópias de trechos de livros dominam este cenário (63\% das respostas). Quanto aos instrumentos de avaliação mais utilizados pelos professores, nos cursos de Pedagogia predominam os trabalhos em grupo $(50,4 \%)$, seguidos de provas escritas discursivas $(31,7 \%)$, ao passo que nos outros cursos de licenciatura as provas escritas são, de longe, a modalidade de avaliação mais empregada $(68,6 \%)$, seguida, em bem menor proporção, dos trabalhos em grupo $(19,1 \%)$. Os demais tipos de avaliação são pouco representativos. Digno de nota é o fato de que metade dos alunos de Pedagogia provavelmente não passa por experiências de avaliação individual nos respectivos cursos.

Teceremos, a seguir, comentários sobre os currículos desenvolvidos nas licenciaturas. 
Formação de professores no Brasil: características e problemas

\section{Tabela 5}

Licenciandos: tipo de ensino médio concluído

\begin{tabular}{|c|c|c|c|c|c|c|c|}
\hline & \multirow{2}{*}{\multicolumn{2}{|c|}{ Pedagogia }} & \multirow{2}{*}{\multicolumn{2}{|c|}{ Licenciaturas }} & & \\
\hline & & & & & & \multicolumn{2}{|c|}{ Total } \\
\hline & & \multirow{2}{*}{$\frac{\mathrm{N}}{15.665}$} & \multirow{2}{*}{$\begin{array}{c}\% \\
39,8\end{array}$} & \multirow{2}{*}{$\frac{\mathbf{n}}{56.528}$} & \multirow{2}{*}{$\begin{array}{c}\% \\
57,9\end{array}$} & \multirow{2}{*}{$\frac{\mathrm{N}}{72.193}$} & \multirow{2}{*}{$\begin{array}{c}\% \\
52,7\end{array}$} \\
\hline (A) & $\begin{array}{l}\text { Comum ou de educação geral, no } \\
\text { ensino regular }\end{array}$ & & & & & & \\
\hline (B) & $\begin{array}{l}\text { Profissionalizante técnico } \\
\text { (eletrônica, contabilidade, agrícola } \\
\text { etc.) no ensino regular }\end{array}$ & 3.801 & 9,7 & 13.768 & 14,1 & 17.569 & 12,8 \\
\hline (C) & $\begin{array}{l}\text { Profissionalizante magistério de } 1^{\mathrm{a}} \text { a } \\
4^{\underline{a}} \text { série (Curso Normal), no ensino } \\
\text { regular }\end{array}$ & 16.461 & 41,8 & 19.501 & 20,0 & 35.962 & 26,2 \\
\hline (D) & Supletivo & 2.603 & 6,6 & 6.067 & 6,2 & 8.670 & 6,3 \\
\hline (E) & Outro curso & 647 & 1,6 & 1.446 & 1,5 & 2.093 & 1,5 \\
\hline & Branco & 81 & 0,2 & 151 & 0,2 & 232 & 0,2 \\
\hline & Respostas inválidas & 101 & 0,3 & 181 & 0,2 & 282 & 0,2 \\
\hline
\end{tabular}

Fonte: MEC/INEP. Questionário socioeconômico - ENADE (2005).

\section{Tabela 6}

Licenciandos: tipo de material mais utilizado durante o curso

\begin{tabular}{|c|l|c|c|c|c|c|c|}
\cline { 3 - 8 } \multicolumn{2}{c|}{} & \multicolumn{2}{c|}{ Pedagogia } & \multicolumn{2}{c|}{ Licenciaturas } & \multicolumn{2}{c|}{ Total } \\
\cline { 2 - 8 } \multicolumn{2}{c|}{} & $\mathbf{n}$ & $\%$ & $\mathbf{n}$ & $\%$ & $\mathbf{n}$ & $\%$ \\
\hline (A) & Livros-texto e/ou manuais & 5.150 & 24,8 & 14.697 & 30,7 & 19.847 & 28,9 \\
\hline (B) & Apostilas e resumos & 8.270 & 39,8 & 15.840 & 33,1 & 24.110 & 35,1 \\
\hline (C) & $\begin{array}{l}\text { Cópias de trechos ou } \\
\text { capítulos de livros }\end{array}$ & 6.914 & 33,3 & 15.054 & 31,4 & 21.968 & 32,0 \\
\hline (D) & $\begin{array}{l}\text { Artigos de periódicos } \\
\text { especializados }\end{array}$ & 261 & 1,3 & 782 & 1,6 & 1.043 & 1,5 \\
\hline (E) & $\begin{array}{l}\text { Anotações manuais e } \\
\text { cadernos de notas }\end{array}$ & 109 & 0,5 & 1.279 & 2,7 & 1.388 & 2,0 \\
\hline & Branco & 43 & 0,2 & 148 & 0,3 & 191 & 0,3 \\
\hline & Respostas inválidas & 27 & 0,1 & 81 & 0,2 & 108 & 0,2 \\
\hline
\end{tabular}

Fonte: MEC/INEP. Questionário socioeconômico - ENADE (2005). 


\section{Tabela 7}

Instrumentos de avaliação utilizados predominantemente pelos professores

\begin{tabular}{|c|c|c|c|c|c|c|c|}
\hline & \multicolumn{2}{|c|}{ Pedagogia } & \multicolumn{2}{|c|}{ Licenciaturas } & \multicolumn{2}{|c|}{ Total } \\
\hline & & $\mathbf{n}$ & $\%$ & $\mathbf{n}$ & $\%$ & $\mathrm{~N}$ & $\%$ \\
\hline (A) & $\begin{array}{l}\text { Provas escritas } \\
\text { discursivas }\end{array}$ & 7.697 & 37,1 & 32.860 & 68,6 & 40.557 & 59,1 \\
\hline (B) & Testes objetivos & 832 & 4,0 & 2.317 & 4,8 & 3.149 & 4,6 \\
\hline (C) & Trabalhos de grupo & 10.470 & 50,4 & 9.129 & 19,1 & 19.599 & 28,5 \\
\hline (D) & Trabalhos individuais & 1.112 & 5,4 & 1.781 & 3,7 & 2.893 & 4,2 \\
\hline (E) & Provas práticas & 548 & 2,6 & 1.470 & 3,1 & 2.018 & 2,9 \\
\hline & Branco & 38 & 0,2 & 187 & 0,4 & 225 & 0,3 \\
\hline & Respostas inválidas & 77 & 0,4 & 137 & 0,3 & 214 & 0,3 \\
\hline
\end{tabular}

Fonte: MEC/INEP. Questionário socioeconômico - ENADE (2005).

\section{Os currículos das licenciaturas}

O projeto "Formação de professores para o ensino fundamental: instituiçôes formadoras e seus currículos" (Gatti et al., 2008, v. 1 e 2; Gatti \& Nunes, 2009) buscou analisar o que se propóe atualmente como disciplinas formadoras nas instituições de ensino superior nas licenciaturas presenciais em Pedagogia, Língua Portuguesa, Matemática e Ciências Biológicas.

Isso foi feito através da análise dos projetos pedagógicos, do conjunto de disciplinas ofertadas e de suas ementas. Para este estudo, foi selecionado um conjunto de cursos de cada licenciatura estudada, segundo critérios de localização por região (Norte, Nordeste, Centro-Oeste, Sudeste e Sul); categoria administrativa (pública - estadual, federal ou municipal - e privada: particular ou comunitária confessional); e organização acadêmica (universidade, centro universitário, faculdade, faculdades integradas ou institutos superiores de educação). As amostras obtidas levaram em consideração a distribuição do total de cursos no país, de acordo com as variáveis mencionadas, 
e apresentam uma distribuição proporcional a essa realidade. $\mathrm{O}$ conjunto amostral foi composto por cursos de licenciatura presenciais, 71 de Pedagogia, 32 de Língua Portuguesa, 31 de Matemática e 31 de Ciências Biológicas, distribuídos proporcionalmente em todo o país.

\section{Formação de professores para os anos iniciais da educação básica}

A licenciatura em Pedagogia responde atualmente pela formação de professores do $1^{\circ}$ ao $4 \% / 5^{\circ}$ ano do ensino fundamental e da educação infantil. O conjunto amostral do estudo citado foi composto por 71 cursos de licenciatura presenciais em Pedagogia, distribuídos em todo o país. Tal conjunto mostra boa representatividade, como já indicado, em relação à distribuição dos cursos pelas regiōes, por categoria administrativa e tipo de instituição. Procedeu-se a um mapeamento de propostas curriculares desses cursos, tendo em conta os diversos tipos de instituiçóes de ensino superior que os oferecem. Nessa amostra encontrou-se uma lista de 3.513 disciplinas (3.107 obrigatórias e 406 optativas). Realizou-se, então, um agrupamento, através das ementas, de forma que se pudesse ter mais clareza do que se propõe como formação inicial de professores nos currículos dos cursos de Pedagogia. A Tabela 8, na página ao lado, sintetiza os achados.

Considerando o conjunto das instituições, há uma quase equivalência entre a proporção de disciplinas que cumprem a função de embasar teoricamente o aluno de Pedagogia, a partir de outras áreas de conhecimento, e aquelas que tratam de questôes ligadas à profissionalização mais específica do professor. Chama a atenção o fato de que apenas 3,4\% das disciplinas ofertadas referem-se à "Didática Geral”. O grupo "Didáticas Específicas, Metodologias e Práticas de Ensino" (o "como" ensinar) representa $20,7 \%$ do conjunto, e apenas $7,5 \%$ das disciplinas são destinadas aos conteúdos a serem ensinados nas séries iniciais do ensino fundamental, ou seja, ao "o que" ensinar. Esse dado torna evidente como os conteúdos específicos das disciplinas a serem ministradas em sala de aula não são objeto dos cursos de formação inicial do professor. Disciplinas relativas ao ofício docente representam apenas $0,6 \%$ desse conjunto. É preciso considerar que, na análise realizada sobre o conteúdo das ementas, ${ }^{1}$ verifica-se que as disciplinas que estariam mais ligadas aos conhecimentos relativos à formação profissional específica também têm em suas ementas uma predominância de 


\section{Tabela 8}

Disciplinas obrigatórias, segundo as categorias de análise desagregadas: licenciaturas em Pedagogia

\begin{tabular}{|c|c|c|c|}
\hline \multicolumn{2}{|r|}{ Categorias } & No & $\%$ \\
\hline \multirow{3}{*}{$\begin{array}{l}\text { Fundamentos } \\
\text { teóricos da educação }\end{array}$} & Fundamentos teóricos da educação & 701 & 22,6 \\
\hline & Didática geral & 106 & 3,4 \\
\hline & Subtotal & 807 & 26,0 \\
\hline \multirow{5}{*}{$\begin{array}{l}\text { Conhecimentos } \\
\text { relativos aos sistemas } \\
\text { educacionais }\end{array}$} & Sistemas educacionais & 165 & 5,3 \\
\hline & Currículo & 158 & 5,1 \\
\hline & Gestão escolar & 140 & 4,5 \\
\hline & Ofício docente & 19 & 0,6 \\
\hline & Subtotal & 482 & 15,5 \\
\hline \multirow{4}{*}{$\begin{array}{l}\text { Conhecimentos } \\
\text { relativos à formação } \\
\text { profissional específica }\end{array}$} & $\begin{array}{l}\text { Conteúdos do currículo da educação } \\
\text { básica (infantil e fundamental) }\end{array}$ & 232 & 7,5 \\
\hline & $\begin{array}{l}\text { Didáticas específicas, metodologias e } \\
\text { práticas de ensino }\end{array}$ & 643 & 20,7 \\
\hline & Tecnologias & 22 & 0,7 \\
\hline & Subtotal & 897 & 28,9 \\
\hline \multirow{5}{*}{$\begin{array}{l}\text { Conhecimentos } \\
\text { relativos às } \\
\text { modalidades e nível } \\
\text { de ensino }\end{array}$} & Educação Especial & 118 & 3,8 \\
\hline & Educação de Jovens e Adultos & 49 & 1,6 \\
\hline & Educação Infantil & 165 & 5,3 \\
\hline & Contextos não escolares & 16 & 0,5 \\
\hline & Subtotal & 348 & 11,2 \\
\hline \multicolumn{2}{|l|}{ Outros saberes } & 173 & 5,6 \\
\hline \multicolumn{2}{|c|}{ Pesquisa e Trabalho de Conclusão de Curso (TCC) } & 217 & 7,0 \\
\hline \multicolumn{2}{|c|}{ Atividades complementares } & 183 & 5,9 \\
\hline \multicolumn{2}{|l|}{ Total } & 3.107 & 100,0 \\
\hline
\end{tabular}

Fonte: Gatti et al. (2008, v. 1).

aspectos teóricos, aqueles que fundamentam as teorias de ensino, contemplando muito pouco as práticas educacionais associadas a esses aspectos. As disciplinas deste grupo trazem ementas que registram preocupação com as justificativas sobre o porquê ensinar, o que, de certa forma, contribuiria para evitar que essas matérias se transformassem em meros receituários. Entretanto, só de forma muito incipiente registram 
o que e como ensinar. Um grande número de ementas registra frases genéricas, não permitindo identificar conteúdos específicos. Há instituições que propóem o estudo dos conteúdos de ensino associados às metodologias, mas, ainda assim, de forma panorâmica e pouco aprofundada. Então, mesmo no conjunto de $28,9 \%$ de disciplinas que podem ser classificadas como voltadas à formação profissional específica, o que sugerem as ementas é que esta formação é feita de forma ainda muito insuficiente, pelo grande desequilíbrio entre teorias e práticas, em favor apenas das teorizações mais abstratas.

Disciplinas relativas à "Educação Infantil” representam apenas $5,3 \%$ do conjunto, e as relativas à "Educação Especial", 3,8\%. Nas ementas encontra-se o mesmo cenário ora descrito. Os cursos estão incorporando tais questôes em um conjunto de disciplinas que acentuam abordagens mais genéricas ou descritivas das questôes educativas, com poucas referências às práticas possíveis e suas lógicas. Alguns poucos cursos fazem o aprofundamento em relação a uma ou outra dessas áreas disciplinares, bem como para Educação de Jovens e Adultos, ou Educação não formal etc., seja mediante a oferta de optativas, seja de tópicos e projetos especiais, mas neles não é possível detectar a predominância de elementos voltados para as práticas docentes propriamente ditas, como uma construção integrada a conhecimentos de fundo. $\mathrm{O}$ estudo das ementas das disciplinas revela, antes de tudo, maior preocupação com o oferecimento de teorias políticas, sociológicas e psicológicas para a contextualização dos desafios do trabalho nesse nível e nessas modalidades de ensino. Isto é importante para o trabalho consciente do professor, mas não suficiente para suas atividades de ensino.

Quando se agrega ao conjunto de disciplinas dedicadas aos fundamentos da educação as disciplinas variadas e gerais, que poderíamos chamar de "outros saberes", e as "atividades complementares", chega-se a quase $40 \%$ do conjunto de disciplinas oferecidas. Por outro lado, fica pouco claro o que nos currículos se qualifica como "atividades complementares”. Estas não são especificadas. Juntando a esse panorama as disciplinas optativas ofertadas, a maioria com o caráter de formação genérica, como foi possível verificar no estudo citado, pode-se inferir que a parte curricular que propicia o desenvolvimento de habilidades profissionais específicas para a atuação nas escolas e nas salas de aula fica bem reduzida.

No conjunto de disciplinas optativas oferecidas pelos cursos, a pesquisa citada verificou que se mantém a tendência de se oferecer, 
sobretudo, disciplinas relativas a fundamentos teóricos da educação, aparecendo ainda disciplinas variadas como "Inglês instrumental", "Nutrição, higiene e saúde", "O escolar e a droga" etc., contemplando um rol de assuntos diversificados, muitos relativos aos temas transversais preconizados pelos Parâmetros Curriculares Nacionais editados em 1997.

Quanto aos estágios supervisionados, lembramos que o número de horas de estágio obrigatório nos cursos de Pedagogia visa proporcionar aos alunos um contato mais aprofundado com as redes de ensino básico. Embora, em princípio, eles constituam espaços privilegiados para a aprendizagem das práticas docentes, não se obteve evidências, neste estudo, sobre como eles vêm sendo de fato realizados. Os dados referentes aos estágios padecem de uma série de imprecisões. Estas praticamente inviabilizam uma análise do que acontece realmente nesses espaços de formação a partir apenas dos currículos. Não obstante, as observaçôes largamente difundidas sobre o funcionamento dos cursos de Pedagogia nos autorizam a sugerir que a maior parte dos estágios envolve atividades de observação, não se constituindo em práticas efetivas dos estudantes de Pedagogia nas escolas. Sobre a validade ou validação desses estágios, também não se encontrou nenhuma referência.

Pode-se perguntar se a formação panorâmica, em geral encontrada nos currículos, é suficiente para o futuro professor vir a planejar, ministrar e avaliar atividades de ensino para os anos iniciais do ensino fundamental e para a educação infantil. A constatação é de que há uma insuficiência formativa evidente para o desenvolvimento desse trabalho. Em síntese, pela análise realizada foi possível constatar que:

a) o currículo proposto pelos cursos de formação de professores tem uma característica fragmentária, apresentando um conjunto disciplinar bastante disperso;

b) a análise das ementas revelou que, mesmo entre as disciplinas de formação específica, predominam as abordagens de caráter mais descritivo e que se preocupam menos em relacionar adequadamente as teorias com as práticas;

c) as disciplinas referentes à formação profissional específica apresentam ementas que registram preocupação com as justificativas sobre o porquê ensinar; entretanto, só de forma muito incipiente registram o que e como ensinar; 
d) a proporção de horas dedicadas às disciplinas referentes à formação profissional específica fica em torno de $30 \%$, ficando $70 \%$ para outro tipo de matérias oferecidas nas instituiçôes formadoras; cabe a ressalva já feita na análise das ementas, segundo a qual, nas disciplinas de formação profissional, predominam os referenciais teóricos, seja de natureza sociológica, psicológica ou outros, com associação em poucos casos às práticas educacionais;

e) os conteúdos das disciplinas a serem ensinadas na educação básica (Alfabetização, Língua Portuguesa, Matemática, História, Geografia, Ciências, Educação Física) comparecem apenas esporadicamente nos cursos de formação e, na grande maioria dos cursos analisados, eles são abordados de forma genérica ou superficial, sugerindo frágil associação com as práticas docentes;

f) poucos cursos propõem disciplinas que permitam algum aprofundamento em relação à educação infantil.

Nas ementas observou-se um evidente desequilíbrio na relação teoria-prática, em favor dos tratamentos mais teóricos, de fundamentos, política e contextualização e que a escola, como instituição social e de ensino, é elemento quase ausente nas ementas, o que leva a pensar numa formação de caráter mais abstrato e pouco integrado ao contexto concreto onde o profissional-professor vai atuar.

Pelo estudo citado pode-se inferir que fica bem reduzida a parte curricular que propicia o desenvolvimento de habilidades profissionais específicas para a atuação nas escolas e nas salas de aula. Assim, a relação teoria-prática como proposta nos documentos legais e nas discussões da área também se mostra comprometida desde essa base formativa.

\section{Licenciaturas em Lingua Portuguesa, Matemática e Ciências Biológicas}

O estudo referido anteriormente também contemplou análises relativas aos currículos e ementas curriculares de cursos de formação inicial de professores em três licenciaturas - em Letras, Matemática e Ciências Biológicas - que são as disciplinas com maior carga horária na educação básica (Gatti et al., 2008 v. 2; Gatti \& Nunes, 2009). Para o estudo da composição das grades curriculares desses três tipos de licenciaturas, também foram elaboradas categorias de análise agrupando as disciplinas em função de sua natureza e objetivos. A amostra dos cursos 
foi estratificada segundo a regiáo do país, dependência administrativa e tipo de instituição, contemplando 32 cursos de licenciatura em Língua Portuguesa, 31 em Matemática e 31 em Ciências Biológicas.

As Tabelas 9, 10 e 11, ao final deste texto, mostram a distribuição das disciplinas em cada uma dessas licenciaturas. Pela análise das grades curriculares e ementas é possível apresentar sinteticamente alguns aspectos que se destacaram:

- Há grande dissonância entre os projetos pedagógicos obtidos e a estrutura do conjunto de disciplinas e suas ementas, nas três licenciaturas, parecendo que aqueles são documentos que não repercutem na realização dos cursos.

- Os cursos de licenciatura em Letras apresentam 51,4\% de sua carga horária em disciplinas relativas aos conhecimentos disciplinares da área, com predominância de Linguística, e apenas $11 \%$ das horas-disciplinas são dedicadas à formação para a docência.

- Nas licenciaturas em Ciências Biológicas a carga horária dedicada à formação específica na área é de $65,3 \%$ e, para formação para docência, registra-se percentual em torno de apenas $10 \%$.

- Os cursos de licenciatura em Matemática se diferenciam por apresentarem um maior equilíbrio entre as disciplinas relativas aos "Conhecimentos específicos da área" e aos "Conhecimentos específicos para a docência", embora as instituiçôes públicas mantenham, em sua maioria, carga horária bem maior para as disciplinas relativas a conhecimentos específicos, espelhando mais a ideia de um bacharelado do que licenciatura.

- Raras instituiçôes especificam em que consistem os estágios e sob que forma de orientação são realizados, se há convênio com escolas das redes, entre outros aspectos.

- A questão das práticas exigidas pelas diretrizes curriculares desses cursos mostra-se problemática, pois ora se coloca que estão embutidas em diversas disciplinas, sem especificação clara, ora aparecem em separado, mas com ementas muito vagas.

- Na maior parte dos ementários analisados não foi observada uma articulação entre as disciplinas de formação específicas 
(conteúdos da área disciplinar) e a formação pedagógica (conteúdos para a docência).

- Um grupo considerável de matrizes curriculares apresenta disciplinas pouco específicas quanto a seus nomes e ementas bastante vagas, encontrando-se, também, redundâncias de conteúdos em disciplinas distintas.

- Saberes relacionados a tecnologias no ensino estão praticamente ausentes.

- Aparecem nos currículos muitas horas dedicadas a atividades complementares, seminários, ou atividades culturais, entre outras, que ficam sem nenhuma especificação quanto ao que se referem (se são atividades acompanhadas por docentes, seus objetivos etc.).

- As disciplinas da categoria "conhecimentos relativos aos sistemas educacionais" registram percentuais inexpressivos de presença em todas as licenciaturas analisadas. Quando se desagrega esta categoria, nota-se que a maior parte das matérias aloca-se em "Estrutura e funcionamento do ensino", ficando aspectos ligados a "Currículo", "Gestão escolar" e "Ofício docente" com percentuais irrisórios.

- Uma parte dessas licenciaturas promove especialização precoce em aspectos que poderiam ser abordados em especializações ou pós-graduações, ou que, claramente, visam a formação de outro profissional que não o professor.

Verificou-se a inexistência de um núcleo compartilhado de disciplinas da área de formação para a docência e é heterogênea a gama de conteúdos com que se trabalha nas disciplinas que mais frequentemente aparecem (Didática, Metodologia e Práticas de Ensino). Ainda assim, constatou-se que é reduzido o número de disciplinas teóricas da área de Educação (Didática, Psicologia da Educação ou do Desenvolvimento, Filosofia da Educação etc.) e que mesmo as disciplinas aplicadas têm espaço pequeno nas matrizes, sendo que estas, na verdade, são mais teóricas que práticas, onde deveria haver equilíbrio entre estes dois eixos. Com as características ora apontadas, com vasto rol de disciplinas e com a ausência de um eixo formativo claro para a docência, presume-se pulverização na formação dos licenciados, o que indica frágil preparação para o exercício do magistério na educação básica. 


\section{Concluindo}

Para Tardif e Lessard (2005), o magistério não pode ser colocado como uma ocupação secundária. Ele constitui um setor nevrálgico nas sociedades contemporâneas, uma das chaves para entender as suas transformações. Nessa perspectiva, torna-se mais do que relevante considerar os dados de pesquisa aqui trazidos. A interação dos diferentes fatores aqui levantados com a estrutura curricular e com as condiçōes institucionais dos cursos de formação de docentes para a educação básica nos sinaliza um cenário preocupante sobre a resultante dessa formação. Isto nos reporta, por exemplo, ao baixo índice de aprovação de licenciados em concursos públicos para professor.

No que concerne à formação de professores, é necessária uma verdadeira revolução nas estruturas institucionais formativas e nos currículos da formação. As emendas já são muitas. A fragmentação formativa é clara. É preciso integrar essa formação em currículos articulados e voltados a esse objetivo precípuo. A formação de professores não pode ser pensada a partir das ciências e seus diversos campos disciplinares, como adendo destas áreas, mas a partir da função social própria à escolarização - ensinar às novas geraçôes o conhecimento acumulado e consolidar valores e práticas coerentes com nossa vida civil.

A forte tradição disciplinar que marca entre nós a identidade docente e orienta os futuros professores em sua formação a se afinarem mais com as demandas provenientes da sua área específica de conhecimento do que com as demandas gerais da escola básica, leva não só as entidades profissionais como até as científicas a oporem resistências às soluçōes de caráter interdisciplinar para o currículo, o que já foi experimentado com sucesso em vários países. A formação de professores profissionais para a educação básica tem que partir de seu campo de prática e agregar a este os conhecimentos necessários selecionados como valorosos, em seus fundamentos e com as mediações didáticas necessárias, sobretudo por se tratar de formação para o trabalho educacional com crianças e adolescentes.

Recebido em julho de 2010 e aprovado em agosto de 2010.

\section{Nota}

1. Foram analisadas 1.498 ementas.

Educ. Soc., Campinas, v. 31, n. 113, p. 1355-1379, out.-dez. 2010 


\section{Referências}

ALVES, N. (Org.). Formação de professores: pensar e fazer. São Paulo: Cortez, 1992.

BRAGA, M.M. A licenciatura no Brasil: um breve histórico sobre o período 1973-1987. Ciência \& Cultura, São Paulo, v. 40, n. 2, p. 16-27, 1988.

CANDAU, V.M.F. (Org.). Novos rumos da licenciatura. Brasília, DF: INEP/PUC-RJ, 1987.

GATTI, B.A. et al. Formação de professores para o ensino fundamental: instituiçôes formadoras e seus currículos; relatório de pesquisa. São Paulo: Fundação Carlos Chagas; Fundação Vitor Civita, 2008. 2v.

GATTI, B.A.; NUNES, M.M.R. (Org.). Formação de professores para o ensino fundamental: estudo de currículos das licenciaturas em Pedagogia, Língua Português, Matemática e Ciências Biológicas. Textos FCC, São Paulo, v. 29, 2009. 155p.

GATTI, B.A.; BARRETO, E.S.S. Professores: aspectos de sua profissionalização, formação e valorização social. Brasília, DF: UNESCO, 2009. (Relatório de pesquisa).

MARQUES, M.O. A reconstrução dos cursos de formação do profissional da educação. Em Aberto, Brasília, DF, n. 54, p. 7-18, 1992.

RAMALHO, B.L.; NUÑEZ, I.B.; GAUTHIER, C. Formar o professor, profissionalizar o ensino. Porto Alegre: Sulina, 2003.

TARDIF, M.; LESSARD, C. O trabalho docente: elementos para uma teoria da docência como profissão de interaçóes humanas. Petrópolis: Vozes, 2005. 
Anexos: Tabelas 9, 10 e 11

\section{Tabela 9}

Carga horária de disciplinas obrigatórias, no conjunto amostral, segundo as categorias de análise desagregadas: licenciaturas em Letras

\begin{tabular}{|c|c|c|c|}
\hline & \multirow{2}{*}{ Categorias } & \multicolumn{2}{|c|}{ Carga horária } \\
\hline & & Horas & $\%$ \\
\hline \multirow{3}{*}{$\begin{array}{l}\text { Fundamentos } \\
\text { teóricos }\end{array}$} & Fundamentos & 4.950 & 6,2 \\
\hline & Didática geral & 1.296 & 1,6 \\
\hline & Subtotal & 6.246 & 7,8 \\
\hline \multirow{5}{*}{$\begin{array}{l}\text { Conhecimentos } \\
\text { relativos aos } \\
\text { sistemas } \\
\text { educacionais }\end{array}$} & Estrutura e funcionamento & 1.490 & 1,9 \\
\hline & Currículo & 1.256 & 1,6 \\
\hline & Gestão escolar & 236 & 0,3 \\
\hline & Ofício docente & 288 & 0,4 \\
\hline & Subtotal & 3.270 & 4,1 \\
\hline \multicolumn{2}{|c|}{ Conhecimentos específicos da área } & 41.031 & 51,4 \\
\hline \multirow{4}{*}{$\begin{array}{l}\text { Conhecimentos } \\
\text { específicos para a } \\
\text { docência }\end{array}$} & $\begin{array}{l}\text { Conteúdos dirigidos à escola } \\
\text { básica }\end{array}$ & 4.179 & 5,2 \\
\hline & $\begin{array}{l}\text { Didáticas esp., metod. e práticas } \\
\text { de ensino }\end{array}$ & 4.531 & 5,7 \\
\hline & Saberes relacionados a tecnologias & 188 & 0,2 \\
\hline & Subtotal & 8.898 & 11,1 \\
\hline \multirow{3}{*}{$\begin{array}{l}\text { Conhecimentos } \\
\text { relativos às } \\
\text { modalidades e nível } \\
\text { de ensino }\end{array}$} & Educação especial & 800 & 1,0 \\
\hline & Educação de Jovens e Adultos & 0 & 0,0 \\
\hline & Subtotal & 800 & 1,0 \\
\hline \multicolumn{2}{|l|}{ Outros saberes } & 12.184 & 15,2 \\
\hline \multicolumn{2}{|l|}{ Pesquisa e TCC } & 2.992 & 3,7 \\
\hline \multicolumn{2}{|c|}{ Atividades complementares } & 4.531 & 5,7 \\
\hline \multicolumn{2}{|l|}{ Total } & 79.952 & 100,0 \\
\hline
\end{tabular}

Fonte: Gatti et al. (2008, v. 2).

Educ. Soc., Campinas, v. 31, n. 113, p. 1355-1379, out.-dez. 2010 


\section{Tabela 10}

Carga horária de disciplinas obrigatórias, no conjunto amostral, segundo as categorias de análise desagregadas: licenciaturas em Matemática

\begin{tabular}{|c|c|c|c|}
\hline & \multirow{2}{*}{ Categorias } & \multicolumn{2}{|c|}{ Carga horária } \\
\hline & & Horas & $\%$ \\
\hline \multirow{3}{*}{$\begin{array}{l}\text { Fundamentos } \\
\text { teóricos }\end{array}$} & Fundamentos & 5.380 & 6,6 \\
\hline & Didática geral & 1.307 & 1,6 \\
\hline & Subtotal & 6.687 & 8,2 \\
\hline \multirow{5}{*}{$\begin{array}{l}\text { Conhecimentos } \\
\text { relativos aos } \\
\text { sistemas } \\
\text { educacionais }\end{array}$} & Estrutura e funcionamento & 1.644 & 2,0 \\
\hline & Currículo & 554 & 0,7 \\
\hline & Gestão escolar & 392 & 0,5 \\
\hline & Ofício docente & 100 & 0,1 \\
\hline & Subtotal & 2.690 & 3,3 \\
\hline \multicolumn{2}{|c|}{ Conteúdos específicos da área } & 27.707 & 34,1 \\
\hline \multirow{4}{*}{$\begin{array}{c}\text { Formação } \\
\text { específica para a } \\
\text { docência }\end{array}$} & Conteúdos dirigidos à escola básica & 15.088 & 18,5 \\
\hline & $\begin{array}{l}\text { Ditáticas esp., metod. e práticas de } \\
\text { ensino }\end{array}$ & 8.551 & 10,5 \\
\hline & Saberes relacionados a tecnologias & 1.356 & 1,7 \\
\hline & Subtotal & 24.995 & 30,7 \\
\hline \multirow{3}{*}{$\begin{array}{l}\text { Conhecimentos } \\
\text { relativos às } \\
\text { modalidades e } \\
\text { nível de ensino }\end{array}$} & Educação especial & 401 & 0,5 \\
\hline & Educação de Jovens e Adultos & 40 & 0,0 \\
\hline & Subtotal & 441 & 0,5 \\
\hline \multicolumn{2}{|l|}{ Outros saberes } & 11.766 & 14,5 \\
\hline \multicolumn{2}{|l|}{ Pesquisa e TCC } & 3.027 & 3,7 \\
\hline \multicolumn{2}{|c|}{ Atividades complementares } & 4.039 & 5,0 \\
\hline \multicolumn{2}{|l|}{ Total } & 81.352 & 100,0 \\
\hline
\end{tabular}

Fonte: Gatti et al. (2008, v. 2). 


\section{Tabela 11}

Carga horária e disciplinas obrigatórias, segundo as categorias de análise desagregadas: licenciaturas em Ciências Biológicas

\begin{tabular}{|c|c|c|c|}
\hline \multirow{2}{*}{\multicolumn{2}{|c|}{ Categorias }} & \multicolumn{2}{|c|}{ Carga horária } \\
\hline & & Horas & $\%$ \\
\hline \multirow{3}{*}{$\begin{array}{l}\text { Fundamentos } \\
\text { teóricos }\end{array}$} & Fundamentos & 4.560 & 5,0 \\
\hline & Didática geral & 1.269 & 1,4 \\
\hline & Subtotal & 5.829 & 6,4 \\
\hline \multirow{5}{*}{$\begin{array}{l}\text { Conhecimentos } \\
\text { relativos aos } \\
\text { sistemas } \\
\text { educacionais }\end{array}$} & Estrutura e funcionamento & 1.428 & 1,6 \\
\hline & Currículo & 847 & 0,9 \\
\hline & Gestão escolar & 244 & 0,3 \\
\hline & Ofício docente & 801 & 0,9 \\
\hline & Subtotal & 3.320 & 3,6 \\
\hline \multicolumn{2}{|c|}{ Conhecimentos específicos da área } & 59.507 & 65,0 \\
\hline \multirow{4}{*}{$\begin{array}{l}\text { Conhecimentos } \\
\text { específicos para } \\
\text { a docência }\end{array}$} & Conteúdos dirigidos à escola básica & 1.358 & 1,5 \\
\hline & $\begin{array}{l}\text { Didáticas esp., metod. e práticas de } \\
\text { ensino }\end{array}$ & 8.007 & 8,7 \\
\hline & Saberes relacionados a tecnologias & 160 & 0,2 \\
\hline & Subtotal & 9.525 & 10,4 \\
\hline \multirow{3}{*}{$\begin{array}{l}\text { Conhecimentos } \\
\text { relativos às } \\
\text { modalidades e } \\
\text { nível de ensino }\end{array}$} & Educação especial & 529 & 0,6 \\
\hline & Educação de Jovens e Adultos & 0 & 0,0 \\
\hline & Subtotal & 529 & 0,6 \\
\hline \multicolumn{2}{|l|}{ Outros saberes } & 3.219 & 3,5 \\
\hline \multicolumn{2}{|l|}{ Pesquisa e TCC } & 3.067 & 3,3 \\
\hline \multicolumn{2}{|c|}{ Atividades complementares } & 6.577 & 7,2 \\
\hline \multicolumn{2}{|l|}{ Total } & 91.573 & 100,0 \\
\hline
\end{tabular}

Fonte: Gatti et al. (2008, v. 2). 